\title{
Influence of surgical treatment and radiotherapy of the advanced intraoral cancers on complete blood count, body mass index, liver enzymes and leukocyte CD64 expression
}

\author{
Tadej Dovšak ${ }^{1}$, Alojz Ihan ${ }^{2}$, Vojislav Didanovič ${ }^{1}$, \\ Andrej Kansky ${ }^{1}$, Nataša Ihan Hren ${ }^{1}$ \\ ${ }^{1}$ Clinical Department of Maxillofacial and Oral Surgery, \\ University Medical Center, Ljubljana, Slovenia; ${ }^{2}$ Institute of Microbiology and Immunology, \\ Faculty of Medicine, University of Ljubljana, Slovenia
}

\begin{abstract}
Background. The aim of our study was to evaluate the influence of the surgery and radiotherapy of the advanced oral squamous cell carcinoma on the complete blood count, body mass index (BMI), acute inflammatory response, liver enzymes and expression of the CD64 index on leukocytes in the peripheral blood.

Patients and method. Venous blood was obtained from 16 patients with advanced oral squamous cell carcinomas treated with radical surgery and external beam radiotherapy. Blood samples were collected prior to surgery (T1), after surgery (T2) and after radiotherapy (T3). Blood samples were analyzed for whole blood count, immunoglobulin G levels, liver enzymes (transaminases (ALT and AST) and gamma-glutamyl trasferase $(\gamma-G T)$ ), inflammatory response markers (C-reactive protein, erythrocyte sedimentation rate, albumin, white blood count, leukocyte count and CD64 expression on leukocytes). Assessment of nutrition was done by calculating the body mass index.

Results. Surgery caused anaemia, trombocytosis, leukocytosis, lymphopenia, rise in acute phase proteins, elevation of CD64 expression on monocytes and neutrophyls, elevation of liver transaminases and lowering of $\gamma$-GT, albumin, protein and bilirubin levels. After radiotherapy haemoglobin, leukocytes, C-reactive protein, erythrocyte sedimentation rate, liver transferases, albumin, bilirubin and proteins returned almost to $\mathrm{T} 1$ levels, levels of lymphocytes, $\gamma$-GT and body mass index lowered. IgG levels remained almost unchanged at T2 and T3. Levels of the CD64 expression on monocytes and neutrophyls also elevated after radiotherapy. Conclusions. Surgery caused a significantly larger acute phase response than radiotherapy, while radiotherapy worsened the already present lymphopenia.
\end{abstract}

Key words: intraoral cancer; surgery; radiotherapy; blood parameters

Received 16 July 2009

Accepted 11 August 2009

Correspondence to: Tadej Dovšak, MD, Clinical Department of Maxillofacial and Oral Surgery, University Medical Center, Ljubljana, Slovenia; Phone: +386 1522 4235; Fax: +386 1522 2495; E mail: tadej. dovsak@kclj.si 


\section{Introduction}

Oral squamous cell carcinoma (OSCC) is the sixth most common neoplasm in the European Union. ${ }^{1}$ Advanced OSCC is treated with surgery and then radiotherapy (RT) and/or chemotherapy. ${ }^{2}$ Five year survival rates for patients with advanced OSCC are below $55 \%{ }^{3}$, so researchers are still searching for better treatment modalities. The single most important factor influencing the outcome of patients with squamous cell carcinomas (SCC) of the upper aerodigestive tract is like at the other malignancies the stage of the disease at the time of initial diagnosis and treatment. ${ }^{4-6}$ Once the tumour is no longer localized but has disseminated to regional lymph nodes, the probability of 5 year survival reduces to nearly half. ${ }^{7-9}$ The patient's long-time prognosis is also worsened by the fact that the new primary SCC of upper aerodigestive tract occurred in $20 \%$ of these patients. ${ }^{10}$

Surgical trauma produces alterations in the hemodynamic, metabolic and immune responses of patients in the postoperative period. This injury response is a dynamic process that follows a specific pattern that has been defined based on clinical and scientific observations. ${ }^{11}$ The initial proinflammatory immune response or systemic inflammatory response syndrome (SIRS) is mediated primarily by the cells of innate immune system. This is followed by a compensatory anti-inflammatory or immunosuppressive phenotype that is mediated primarily by cells of the adaptive immune system, which predisposes the host to septic complications ${ }^{9}$ and may be also promotes the tumour growth and metastases. ${ }^{13,14}$ Cell mediated immunity is suppressed for several days after surgery and more invasive procedures lead to deeper and longer immunosuppression. ${ }^{14,15}$

The role of RT for OSCC treatment is well established; modern equipment and techniques have minimized morbidity. ${ }^{16}$ Toxicity is related to site and dose; acute toxicity is related to the inflammatory process induced within the radiation field. These effects occur to some degree in the majority of patients, but they are self-limited in duration. The presence of late toxicity is determined by the total dose of radiation given and not by the daily dose or fraction size. ${ }^{17-19}$ Although lymphocytes are highly sensitive to radiation damage ${ }^{19,20}$ this toxicity is not usually assessed.

The aim of our study was to evaluate the effect of major surgical procedures and RT of advanced OSCC on the complete blood count, body mass index (BMI), acute inflammatory response, liver enzymes and expression of the CD64 index on leukocytes in the peripheral blood by the prospective non-randomized study.

\section{Patients and methods}

Our prospective non-randomized study was running from 2007 to 2009 on the Clinical Department for Oral and Maxillofacial Surgery, University Clinical Center in Ljubljana. Sixteen patients with advanced OSCC were selected. The study group included 12 men and 4 women with median age 61 years (range 42-80 years). All were Stage III and IV according to the American Joint Committee on Cancer staging. ${ }^{21}$ Inclusion criteria were that surgery and radiotherapy were the only treatment modalities. The local Ethics Committee of the Republic of Slovenia ensured that research protocol and appropriate written consent was obtained from each patient.

Blood samples T1 were collected between 1 to 17 days before surgery (mean $\pm \mathrm{SD} ; 8.9 \pm 5.9$ ). All patients were surgically treated with en bloc excision of tumour and modified neck dissection (five of them with bilateral) and subsequent re- 
construction with flaps (9 with free flaps: 6 radial forearm, 1 iliac crest, 1 anterior lateral thigh, 1 fibula; 3 with pedicled flaps: 2 pectoralis major muscle, 1 temporalis muscle). Median blood loss during operation was $430 \mathrm{ml}$ (range $200-1000 \mathrm{ml}$ ) which was assessed by the anaesthesiologist and surgeon. In all but one patient, temporary tracheotomy was performed at the time of operation. All patients had confirmed clear margins with frozen sections at the time of operation. In one patient, revision of the operative field was required immediately after operation because of haemorrhage. All free flaps were viable and functioning. The tracheotomy tube was removed at median day 6 (range 3-15). All patients were fed by nasogastric tubes (NGTs) for the median time of 9 days (range 5-15). Six patients received postoperative transfusion of concentrated erythrocytes for the correction of haemoglobin levels bellow $90 \mathrm{mg} / \mathrm{l}$. All patients were treated with antibiotics for the median time of 8 days (range 5-10). Blood samples T2 were taken between 8 and 26 days after surgery (mean \pm SD: $15.4 \pm 4.4$ ).

Patients were irradiated with an external beam on the $6 \mathrm{MV}$ linear accelerator. They received between 58 and 66 Gy (mean \pm SD: $60.5 \pm 1.9$ ), divided on 2 Gy daily fractions, five times a week. This RT was applied within 6 weeks after the surgery. No patient received hyperfractionated RT or chemotherapy. Blood samples T3 have been collected from 28 days up to 128 days postRT (mean \pm SD: $56.6 \pm 36.9$ ).

At the time of blood sampling all patients were weighted and their height was measured at T1. These measures were used to calculate body mass index (BMI, $\left.\mathrm{kg} / \mathrm{m}^{2}\right)$.

\section{Blood sampling}

The blood samples were taken from the cubital vein. 1 EDTA-containing test tube $(5 \mathrm{ml})$ of peripheral blood was obtained for haematological, biochemical and cytometrical laboratory tests.

\section{Expression of CD64 on neutrophils and monocytes}

Expression of CD64 on neutrophils, monocytes and lymphocytes was measured by quantitative flow cytometry with a FACSCalibur flow cytometer (Becton Dickinson, NY, USA) and FACSCanto flow cytometer (Becton Dickinson, CD, USA) using the Leuko64TM assay (Trillium Diagnostics, LLC, Maine, USA). The assay is for research use only and is composed of three antibodies with specificities to CD64 (clones 22 and 32.2, both fluorescein isothiocyanate (FITC) conjugated) and a fluorescence bead suspension with three fluorescence signals (green fluorescence due to FITC, orange fluorescence similar to $\mathrm{PE}$ and red fluorescence of starfire red) for unique identification of beads, and used for instrument calibration and standardization of leukocyte CD64 expression in human blood. The sample preparation and flow cytometer setup were based on the manufacturer's instructions. Briefly, $50 \mu \mathrm{L}$ of whole blood, or diluted whole blood to adjust leukocyte concentration to less than $25 \times 109 / \mathrm{L}$, was incubated for 15 minutes in the dark at room temperature with a mixture of murine monoclonal antibodies followed by red cell lyses with an ammonium-chloride-based solution (Trillium Lyse). Fluorescence beads were then added and flow cytometer analysis was performed on a minimum of 50,000 leukocytes. Data analysis for fluorescence intensity was performed by CellQuest software (Becton Dickinson, CA, USA). MFI was measured as a linearized value of log scale on monocytes (green, positive control, measuring CD64 expression), neutrophils (blue, measuring CD64 expression), and beads (aqua blue, measuring FITC and PE expres- 
Table 1. Median values; SD of leukocytes, platelets, neutrophils and lymphocytes $\left(10^{*} 9 / \mathrm{L}\right)$, erythrocytes $\left(10^{*} 12 / \mathrm{L}\right)$ and Hb levels $(\mathrm{g} / \mathrm{L})$ in observed times (before surgery (T1) and after surgery (T2); after RT - T3) and their normal values. The significant differences $(\mathrm{p}<0.05)$ according to the preceding value are marked by *

\begin{tabular}{|c|c|c|c|c|}
\hline Blood & T1 & $\mathrm{T} 2$ & T3 & Normal values \\
\hline Leu $(10 * 9 / \mathrm{L})$ & $8.37(3.7)$ & $9.06(2.9)$ & $7.16(2.3)^{*}$ & $4.0-10.0$ \\
\hline Erci $\left(10^{*} 12 / \mathrm{L}\right)$ & $4.16(0.7)$ & $3.73(0.5)^{*}$ & $4.33(0.4)^{*}$ & $4.20-6.30$ \\
\hline $\mathrm{Hb}(\mathrm{g} / \mathrm{L})$ & $138.38(14,2)$ & $119.06(10.9)^{*}$ & $134.31(13.8)^{*}$ & $120-180$ \\
\hline $\mathrm{Pt}\left(10^{*} 9 / \mathrm{L}\right)$ & (94) & $(180)^{*}$ & $(79)^{*}$ & $140-340$ \\
\hline Neutr $(10 / 9 / L)$ & $5.1 \quad(2.7)$ & $6.2(2.5)^{*}$ & $5.1(2.0)^{*}$ & $1.6-7.5$ \\
\hline $\operatorname{Lym}(10 * 9 / \mathrm{L})$ & $2.10(0.8)$ & $1.96(0.7)$ & $1.13(0.6)^{*}$ & $1.4-3.3$ \\
\hline
\end{tabular}

Legend: Leu - leukocytes; Erci - erythrocytes; Hb - haemoglobin; Pt - platelets; Neutr neutrophils; Lym - lymphocytes

sion). Index calculation was performed by Leuko64 QuantiCalc software (Trillium Diagnostics, Main, USA). Index measurements were derived by the ratio of linearized MFI of the cell population to the FITC signal from the beads. An internal negative control of the assay was provided by the automated measurement of the lymphocyte CD64 index, which had to be less than 1.0, and an internal positive control of the assay was provided by automated measurement of the monocyte CD64 index, which had to be more than 3.0. Flow cytometry was performed up to 36 hours after blood sampling. Before the beginning of the study, the influence of delayed sample analysis was done and no significant difference in levels of CD64 expression was detected in the first 36 hours after blood sampling. Isotype-control antibodies were routinely used in each experiment to detect nonspecific staining; however the calculation of CD64 MFI was done without subtracting isotype-control MFI in order to accurately compare the ratio (index) of linearized MFI to MFI alone.

\section{Statistics}

Data were presented as the median and 95\% confidence interval of the mean. Comparison between groups was made using the unpaired Mann-Whitney test and analysis of variance (ANOVA). Proportions of patients

Table 2. Median values, SD of BMI $(\mathrm{kg} / \mathrm{m} 2)$, levels of proteins, albumin, $\operatorname{IgG}(\mathrm{g} / \mathrm{L})$, bilirubin $(\mu \mathrm{mol} / \mathrm{L}), \mathrm{ALT}, \mathrm{AST}$ and $\gamma$-GT $(\mu \mathrm{kat} / \mathrm{L})$ in observed times. The significant differences $(\mathrm{p}<0.05)$ according to the preceding value are marked by *

\begin{tabular}{|c|c|c|c|c|}
\hline Nutrition\&Liver & T1 & $\mathrm{T} 2$ & T3 & Normal values \\
\hline BMI (kg/m2) & $23.03(4.8)$ & $22.18(4.8)^{*}$ & $21.11(4.6)^{*}$ & $19-25$ \\
\hline Proteins (g/L) & $73.56(5.5)$ & $71.94(4.4)$ & $75.88(4.6)^{*}$ & $65-80$ \\
\hline Albumin (g/L) & $41.94(4.8)$ & $38.81(3.2)^{*}$ & $42.06(4.9)^{*}$ & $32-55$ \\
\hline $\operatorname{IgG}(\mathrm{g} / \mathrm{L})$ & $12.46(3.7)$ & $12.15(2.3)$ & $12.78(2.6)$ & $6.90-14.00$ \\
\hline Bilirubin $(\mu \mathrm{mol} / \mathrm{L})$ & $13.19(7.1)$ & $6.75(2.7)^{*}$ & $10.19(5.2)^{*}$ & $<17$ \\
\hline AST $(\mu \mathrm{kat} / \mathrm{L})$ & $0.53(0.3)$ & $0.58(0.4)$ & $0.43(0.3)$ & $<0.58$ \\
\hline ALT $(\mu \mathrm{kat} / \mathrm{L})$ & $0.35(0.1)$ & $0.69(0.5)^{*}$ & $0.42(0.3)^{*}$ & $<0.74$ \\
\hline$\gamma$-GT $(\mu \mathrm{kat} / \mathrm{L})$ & $(2.7)$ & $1.34(1.0)$ & $0.52(0.3)^{*}$ & $<0.92$ \\
\hline
\end{tabular}




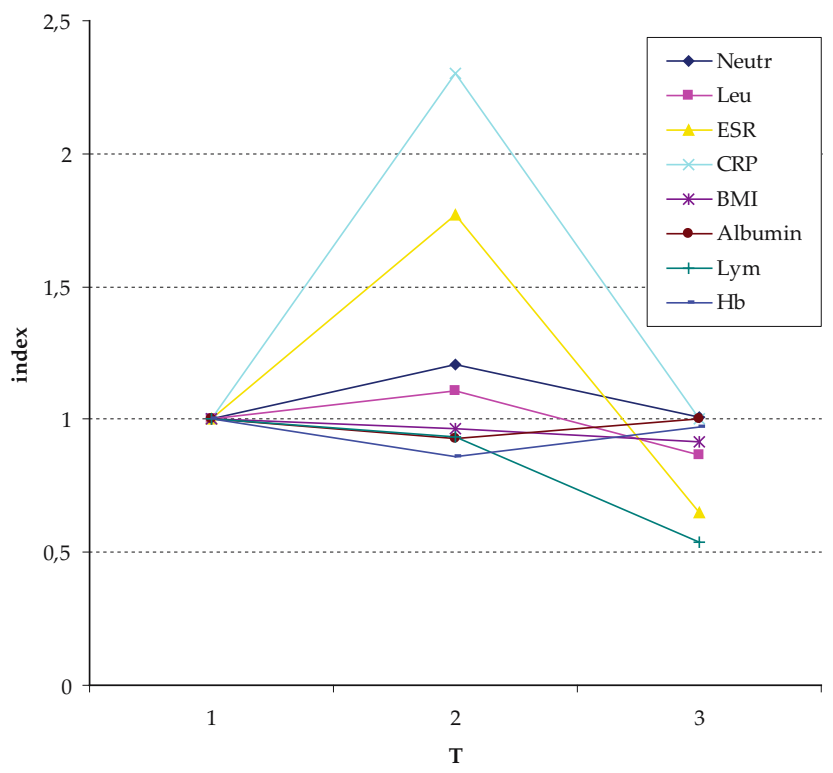

Figure 1. The average values of neutrophils, leukocytes, ESR, CRP, BMI, albumin, lymphocytes and haemoglobin are indexed on T1 value. Only the T2 values of leukocytes and lymphocytes did not reach the statistically significant level $(\mathrm{p}<0.05)$.

were compared by the $\chi 2$ test. The differences were considered to be statistically significant at the level of $\mathrm{p}<0.05$. The statistical analysis was performed using Statistical Package for the Social Sciences for Windows, version 12.0 (SPSS Inc., Chicago, USA).

\section{Results}

Blood cell counts and $\mathrm{Hb}$ results are presented in Table 1 at T1, T2 and T3 with the normal values of these parameters in our referential laboratory.

Values of markers of nutrition and liver enzymes at sampling times are presented in Table 2 with the normal values of these parameters in our referential laboratory.

Results of values at T1, T2 and T3 of the acute phase proteins together with neutrophils, leukocytes and indexes of CD64 expression on the monocytes and neutrophils are presented in Table 3.
The advanced surgical procedures of OSSC had caused anemia, thrombocytosis, leukocytosis, lymphopenia, rise in acute phase proteins (erythrocyte sedimentation rate (ESR) and C-reactive protein (CRP)), elevation of CD64 expression on monocytes and neutrophils, elevation of liver transaminases and lowering of $\gamma$-GT, albumin, protein and bilirubin levels. After RT, haemoglobin, leukocytes, ESR, CRP, liver transferases, albumin, bilirubin and proteins returned almost to $\mathrm{T} 1$ levels; levels of lymphocytes, $\gamma$-GT and BMI decreased (Figure 1). IgG levels remained almost unchanged at T2 and T3. Levels of the CD64 expression on monocytes and neutrophils also elevated after RT.

\section{Discussion}

The purpose of our study was to establish the systemic influences of the surgical treatment and RT for the OSSC. Our results showed that advanced surgical procedures of OSSC caused a significantly larger acute phase response than radiotherapy, while radiotherapy worsened the already present lymphopenia. IgG levels remained almost unchanged at T2 and T3. Levels of the CD64 expression on monocytes and neutrophils also elevated after RT.

The postsurgical anaemia observed in our patients has been expected. During major surgery on the head and neck substantial blood loss may occur, varying between mean values of 500-1500 ml. ${ }^{22,23}$ This results in a lower haemoglobin level after surgery and thus before radiotherapy, in particular when the haemoglobin level is 
Table 3. Median values and SD of the markers of inflammatory response (leukocytes, neutrophils, ESR, CRP, indexes of CD64 on monocytes and neutrophils) at T1, T2 and T3. The significant differences $(p<0.05)$ according to the preceding value are marked by *

\begin{tabular}{cclllllll}
\hline Inflammation & \multicolumn{3}{c}{ T1 } & \multicolumn{2}{c}{ T2 } & \multicolumn{2}{c}{ T3 } & Normal values \\
\hline Leu $\left(10^{*} 9 / \mathrm{L}\right)$ & $8.37(3.7)$ & $9.06(2.9)$ & 77.16 & $(2.3)^{*}$ & $4.0-10.0$ \\
Neutr $(10 / 9 / \mathrm{lL})$ & 5.1 & $(2.7)$ & 6.2 & $(2.5)^{*}$ & 5.1 & $(2.0)^{*}$ & $1.6-7.5$ \\
ESR $(\mathrm{mm} / \mathrm{h})$ & 33 & $(24)$ & 58 & $(21)^{*}$ & 37 & $(18)^{*}$ & $<15$ \\
CRP $(\mathrm{mg} / \mathrm{L})$ & 5 & $(6)$ & $11.5(18)^{*}$ & 5 & $(52)^{*}$ & $<5$ \\
iCD64 mono. & $6.67(1.0)$ & $7.92(1.9)^{*}$ & $8.67(5.7)^{*}$ & $4.34-8.70$ \\
iCD64 neutr. & $0.64(0.1)$ & $0.75(0.2)^{*}$ & $0.95(0.6)^{*}$ & $0.45-2.16$ \\
\hline
\end{tabular}

Legend: Leu - leukocytes; Neutr - neutrophils; ESR - erythrocyte sedimentation rate; CRP - C-reactive protein; iCD64 mono-index of CD64 expression on monocytes; iCD64 neutr - index of CD64 expression on neutrophils

kept relatively low to prevent thrombosis in a microvascular free flap reconstruction. ${ }^{24}$ Anaemia is considered to be associated with hypoxia ${ }^{21}$ resulting in worse clinical outcome as tumour hypoxia decreases the efficacy of radiation therapy as a result of decreased radiosensitivity ${ }^{26-28}$ and because hypoxia itself may induce genetic alterations that are associated with worse outcome. ${ }^{29}$ The blood loss in our study was low but still moderate anaemia developed. The cut off point of haemoglobin for transfusion used in our department is $90 \mathrm{~g} / \mathrm{l}$ and 6 of patients were therefore given blood transfusion postoperatively. Blood transfusion is known to have some immunomodulatory effect ${ }^{30}$ that might predict outcome. ${ }^{31,32}$ Studies regarding anaemia prior to RT have sown that anaemic patients have lower locoregional control and lower overall survival. ${ }^{27,33-35}$ Proposed levels of $\mathrm{Hb}$ prior to $R T$ is $120 \mathrm{~g} / \mathrm{l}^{36}$, which was also the level of haemoglobin in our study after surgery.

After surgery there was a statistically significant rise in the number of platelets that returned within normal limits after RT in our results. This reactive thrombocytosis is known to be triggered by tissue trauma and major surgical procedures. ${ }^{37}$ In a recent study $\mathrm{Lu}$ et al. showed that preoperative thrombocytosis was an independent prognostic factor of shorter survival in OSCC. ${ }^{38}$
In our study none of them had preoperative trombocytosis.

Leukocytes and neutrophil levels at all observed times were within normal values, although neutrophil levels elevated postsurgically also indicating inflammatory response. IgG levels did not change during treatment and were within normal limits; it was reported that IgG levels are normal in OSCC $^{39}$ and treatment modalities do not affect IgG levels. ${ }^{40}$

Major surgery is also a cause of transient lymphocyte decline ${ }^{41,42}$, that returns to normal levels 5-8 days after surgery. ${ }^{43}$ Since all blood tests were taken 8 days after surgery, we did not observe any statistically significant changes in lymphocyte decline after surgery. A study done by Kuss et al. has shown that lymphopenia persisted for more than 2 years after surgical removal of the tumour (squamous cell carcinoma of the head and neck $)^{44}$, which is not consistent with our findings.

Irradiation of the areas with abandoned bone marrow causes severe lymphopenia. ${ }^{45,46}$ But even irradiation of the limited anatomical areas such as neck can cause lymphopenia lasting over 2 years, especially regarding some subpopulations of $\mathrm{T}$ lymphocytes. ${ }^{44,47,48}$ Also in our study, RT almost halved the levels of lymphocytes. With RT, vertebrae are mostly spared from irradiation; also, the thymus is not in the radiation field and most of the neck nodes are removed at the time of operation. Possible mechanisms to explain lymphopenia are damage to lymphocytes in large vessels, and lymphatics in the radiation field at the time of irradiation. Also in older patients, there 
is a limited thymopoesis even more potentiated with liver insufficiency and poor nutrition. ${ }^{48}$ A longer period of observation will be required to compare our results with the studies that have shown a long lasting decline of lymphocytes after RT. ${ }^{48}$

Acute phase proteins are a family of inflammatory proteins synthesized by the liver whose levels change in response to injury, infection and neoplasia. ESR has been routinely used in the diagnosis of infections for decades. CRP levels rise approximately 4 to 12 hours after surgery and peak at 24 to 72 hours. Subsequently, CRP levels remain elevated for nearly 2 weeks. ${ }^{49}$ All forms of significant tissue damage triggers acute phase response as well as different types of cancer, especially, when they are extensive and metastastatic. ${ }^{50}$ High levels of ESR have also been found to be evidence of cancer progression in different malignancies and were correlated with poor prognosis. ${ }^{51}$ Studies reported the prognostic value of the preoperative CRP in oesophageal, gastric, ovarian and colorectal carcinomas. ${ }^{52-54}$ Recently a study from Khandavilli et al. reported that increased preoperative CRP was associated with worse overall survival in patients with OSCC. ${ }^{55}$ In our study mean CRP levels at T1 were at the upper border of the normal range and in only three patients it was higher. By expanding the study and by enrolling more patients it would be interesting to compare patients with high CRP levels to their chances of overall survival. Results of levels of ESR and CRP showed that surgery caused a significant increase in the levels of ESR and CRP, and that at T3, levels returned almost to T1 levels. ESR levels were elevated even before surgery which is consistent with findings that acute and subacute changes of the ESR are most commonly due to malignancy, infection or inflammatory process. ${ }^{56,57}$ Tang et al. also found no increase of CRP after RT in patients with cervical carcinoma ${ }^{58}$ while some studies reported on considerably elevated levels after RT in patients with head and neck carcinomas and cervical cancer. ${ }^{59,60}$ One of the reasons why levels of CRP and ESR levels returned to T1 levels after RT in our study is that blood samples at T3 were taken from 28 to 128 days after RT and in the above mentioned studies immediately after RT.

CD64 is a high-affinity and restricted isotype-specificity Fc $\gamma$ RI receptor expressed on macrophages, monocytes, neutrophils, and eosinophils. ${ }^{61}$ During bacterial infections, however, the neutrophil expression of CD64 is markedly increased. ${ }^{63-65}$ Studies have confirmed that the level of CD64 expression is significantly higher in patients with infectious SIRS as compared to patients with noninfectious SIRS as well as adults and children. ${ }^{66,67}$ All the indexes in our group were within the normal range, although surgery is known to elevate the levels of CD64 expression on monocytes and neutrophils. ${ }^{68,69}$ The reason for this is due to the fast kinetics of these indexes making them useful for detecting bacterial infections and monitoring response to treatment. Levels declined 3 days after surgery ${ }^{69}$ and all of our T2 blood samples were taken after day 3. However, there was a steady incline in indexes, which might be due to the increased microorganism invasion, most probably from the gut mucosa.

BMI in our patients steadily dropped throughout the course of the treatment (Table 2, Figure 1). Nieto et al. showed in their study that BMI lower than 22 for smokers and drinkers significantly increases odds ratio for developing oral cancer. ${ }^{70}$ Since alcohol and tobacco abuse are the two most important etiological factors for $\mathrm{OSSC}^{71}$, only 2 of our patients were nonsmokers and all admitted to drinking modestly. We decided to check BMI regularly in OSCC patients because of the known fact that cachexia-anorexia syndrome occurs in 
30 to $80 \%$ of cancer patients. ${ }^{72}$ Although BMI did not reach the malnutrition level it still points to the need of an even better nutritional support of these patients.

\section{Conclusions}

Because of the low survival rate of patients with OSCC, we decided to evaluate many parameters of these patients in a prospective study. We studied the influence of surgery and radiotherapy on our patients. The major surgical procedure had caused anaemia, thrombocytosis, leukocytosis, lymphopenia, rise in acute phase proteins, elevation of CD64 expression on monocytes and neutrophils, elevation of liver transaminases and lowering of $\gamma-\mathrm{GT}$, albumin, protein and bilirubin levels. After radiotherapy, haemoglobin, leukocytes, C-reactive protein, erythrocyte sedimentation rate, liver transferases, albumin, bilirubin and protein levels returned almost to T1 levels; levels of lymphocytes, $\gamma$-GT and BMI decreased. IgG levels remained almost unchanged during the therapies. Surgery caused a significantly larger acute phase response than RT, while RT worsened the already present lymphopenia. Levels of CD64 expression on monocytes and neutrophils increased after RT.

The major influences of surgical procedures were transient and reactive, while those after RT caused a more profound and long lasting effects. The results obtained from our study are the starting points for further investigations of OSCC patients.

\section{References}

1. Black RJ, Bray F, Ferlay J, Parkin DM. Cancer incidence and mortality in the European Union: cancer registry data and estimates of national incidence for 1990. Eur J Cancer 1997; 33: 1075-107.
2. Forastiere A, Koch W, Trotti A, Sidransky D. Head and Neck Cancer. N Engl J Med 2001; 345: 1890900 .

3. Rogers SN, Brown JS, Woolgar JA, Lowe D, Magennis P, Shaw RJ, et al. Survival following primary surgery for oral cancer. Oral Oncol 2009; 45: 201-11.

4. Samardziski M, Zafiroski G, Tolevska C, KalicaninMarkovska M, Doncovska D, Anevska V, et al. Treatment of patients with "high grade" extremity localized chondrosarcoma. Preliminary results. Radiol Oncol 2009; 43: 187-94.

5. Kovač V, Smrdel U. Meta-analyses of clinical trials in patients with non-small cell lung cancer. Neoplasma 2004; 51: 334-40.

6. Oblak I. Anderluh F, Velenik V. Postoperative radiochemotherapy for gastric adenocarcinoma: long term results. Radiol Oncol 2009; 43: 274-81.

7. Shah JP. Patterns of cervical lymph node metastasis from squamous carcinomas of the upper aerodigestive tract. Am J Surg 1990; 160: 405-9.

8. Shah JP, Candela FC, Poddar AK. The patterns of cervical lymph node metastases from squamous carcinoma of the oral cavity. Cancer 1990; 66: 10913.

9. Shah JP, Andersen PE. The impact of patterns of nodal metastasis on modifications of neck dissection. Ann Surg Oncol 1994; 1: 521-32.

10. Hashibe M, Ritz B, Le AD, Li G, Sankaranarayanan $\mathrm{R}$, Zhang ZF. Radiotherapy for oral cancer as a risk factor for second primary cancers. Cancer Lett 2005; 220: 185-95.

11. Ni Choileain N, Redmond HP. Cell response to surgery. Arch Surg 2006; 141: 1132-40.

12. Faist E, Schinkel C, Zimmer S. Update on the mechanisms of immune suppression of injury and immune modulation. World J Surg 1996; 20: 454-9.

13. Weese JL, Ottery FD, Emoto SE. Do operations facilitate tumor growth? An experimental model in rats. Surgery 1986; 100: 273-7.

14. Sietses C, Beelen RH, Meijer S, Cuesta MA. Immunological consequences of laparoscopic surgery, speculations on the cause and clinical implications. Langenbecks Arch Surg 1999; 384: 250-8.

15. Carter JJ, Whelan RL. The immunologic consequences of laparoscopy in oncology. Surg Oncol Clin N Am 2001; 10: 655-77. 
16. Stavrev P, Schinkel C, Stavreva N, Fallone BG. How well are clinical gross tumor volume DVHs approximated by an analytical function? Radiol Oncol 2009; 43: 132-5.

17. Hellman S. Principles of cancer management: radiation therapy. In: De Vita Jr. VT, Hellman S, Rosenberg SA, editors. Cancer principles and practice of oncology. 5th Edit. New York: LippincotRaven; 1997. p. 303-33.

18. Purdy JA, Klein EE. Photon external beam dosimetry and treatment planning. In: Perez CA, Brady LW, Halperin EC, editors. Principles and Practice of Radiation Oncology. Philadelphia: Lippincot Williams\&Wilkins; 2008. p. 166-89.

19. Amdur RJ, Parsons JT, Mendenhall WM, Million RR, Stringer SP, Cassisi NJ. Postoperative irradiation for squamous cell carcinoma of the head and neck: an analysis of treatment results and complications. Int J Radiat Oncol Biol Phys 1989; 16: 25-36.

20. Popanda O, Ebbeler R, Twardella D, Helmbold I, Gotzes F, Schmezer P, et al. Radiation-induced DNA damage and repair in lymphocytes from breast cancer patients and their correlation with acute skin reactions to radiotherapy. Int J Radiat Oncol Biol Phys 2003; 55: 1216-25.

21. Greene FL, Page DL, Fleming ID, Fritz AG, Balch CM, Haller DG, et al, editors. AJCC Cancer Staging Manual. 6th Edit. New York: Springer; 2002.

22. Smeele LE, Irish J, Gullane PJ, Neligan P, Brown $\mathrm{DH}$, Rotstein LE. A retrospective comparison of the morbidity and cost of different reconstructive strategies in oral andoropharyngeal carcinoma. Laryngoscope 1999; 109: 800-4.

23. Scott SN, Boeve TJ, McCulloch TM, Fitzpatrick KA, Karnell LH. The effects of epoetin alfa on transfusion requirements in head and neck cancer patients: a prospective, randomized, placebocontrolled study. Laryngoscope 2002; 112: 1221-9.

24. van de Pol SM, Doornaert PA, de Bree R, Leemans $\mathrm{CR}$, Slotman BJ, Langendijk JA. The significance of anemia in squamous cell head and neck cancer treated with surgery and postoperative radiotherapy. Oral Oncol 2006; 42: 131-8.

25. Becker A, Stadler P, Lavey RS, Hänsgen G, Kuhnt $\mathrm{T}$, Lautenschläger $\mathrm{C}$, et al. Severe anemia is associated with poor tumor oxygenation in head and neck squamous cell carcinomas. Int J Radiat Oncol Biol Phys. 2000; 46: 459-66.
26. van Acht MJ, Hermans J, Boks DE, Leer JWH. The prognostic value of hemoglobin and a decrease hemoglobin during radiotherapy in laryngeal carcinoma. Int J Radiat Oncol Biol Phys 1992; 23: 22935.

27. Lee WR, Berkey B, Marcial V, Fu KK, Cooper JS, Vikram B, et al. Anemia is associated with decreased survival and increased locoregional failure in patients with locally advanced head and neck carcinoma: a secondary analysis of RTOG 85-27. Int J Radiat Oncol Biol Phys 1998; 42: 1069-75.

28. Gray LH, Conger AD, Ebert M, Hornsey S, Scott OC. The concentration of oxygen dissolved in tissues at the time of irradiation as a factor in radiotherapy. Br J Radiol 1953; 26: 638-48.

29. Vaupel P, Kelleher D, Höckel M. Oxygenation status of malignant tumors: pathogenesis of hypoxia and significance for tumor therapy. Sem Oncol 2001; 28: 29-35.

30. Brand A, Houbiers JGA. Clinical studies of blood transfusion and cancer. In: E.C. Vamvakas and M.A. Blajchman, editors. Immunomodulatory Effects of Blood Transfusion. AABB Press; 1999, 145-190.

31. Johnson JT, Taylor FH, Thearle PB. Blood transfusion and outcome in stage III head and neck carcinoma. Arch Otolaryngol Head Neck Surg 1987; 113: 307-10.

32. Jones KR, Weissler MC. Blood transfusion and other risk factors for recurrence of cancer of the head and neck. Arch Otolaryngol Head Neck Surg 1990; 116: 304-9.

33. van de Pol SM, Doornaert PA, de Bree R, Leemans $\mathrm{CR}$, Slotman BJ, Langendijk JA. The significance of anemia in squamous cell head and neck cancer treated with surgery and postoperative radiotherapy. Oral Oncol 2006; 42: 131-8.

34. Nguyen-Tan PF, Le QT, Quivey JM, Singer M, Terris DJ, Goffinet DR, et al. Treatment results and prognostic factors of advanced T3-4 laryngeal carcinoma: the university of California, San Francisco (UCSF) and Stanford university hospital (SUH) experience. Int J Radiat Oncol Biol Phys 2001; 50: 1172-80.

35. Velenik V. Locally recurrent rectal cancer: treatment options. Radiol Oncol 2009; 43: 144-51. 
36. Oblak I, Strojan P, Zakotnik B, Budihna M, Smid L. Hemoglobin as a factor influencing the outcome in inoperable oropharyngeal carcinoma treated by concomitant radiochemotherapy. Neoplasma 2003; 50: $452-8$.

37. Griesshammer M, Bangerter M, Sauer T, Wennauer R, Bergmann L, Heimpel H. Aetiology and clinical significance of thrombocytosis: analysis of 732 patients with an elevated platelet count. J Intern Med 1999; 245: 295-300.

38. Lu CC, Chang KW, Chou FC, Cheng CY, Liu CJ. Association of pretreatment thrombocytosis with disease progression and survival in oral squamous cell carcinoma. Oral Oncol 2007; 43: 283-8.

39. Scully C. Immunological abnormalities in oral carcinoma and oral keratosis. J Maxillofac Surg 1982; 10:113-5.

40. Khanna NN, Das SN, Khanna S. Serum immunoglobulins in squamous cell carcinoma of the oral cavity. J Surg Oncol 1982; 20: 46-8.

41. Brivio F, Lissoni P, Tisi E, Erba L, Barni S, Tancini $\mathrm{G}$, et al. Effects of a preoperative therapy with IL2 on surgery induced lymphocytopenia in cancer patients. Oncology 1992; 49: 215-8.

42. Brivio F, Lissoni P, Tisi E, Erba L, Barni S, Tancini $\mathrm{G}$, et al. Effects of a preoperative therapy with interleukin-2 on surgery-induced lymphocytopenia in cancer patients. Oncology 1992; 49: 215-8.

43. Hamid J, Bancewicz J, Brown R, Ward C, Irving $\mathrm{MH}$, Ford WL. The significance of changes in blood lymphocyte populations following surgical operations. Clin Exp Immunol 1984; 56: 49-57.

44. Kuss I, Hathaway B, Ferris RL, Gooding W, Whiteside TL: Decreased absolute counts of T lymphocyte subsets and their relation to disease in squamous cell carcinoma of the head and neck. Clin Cancer Res 2004; 10: 3755-62.

45. Uh S, Lee SM, Kim HT, Chung Y, Kim YH, Park C, et al. The effect of radiation therapy on immune function in patients with squamous cell lung carcinoma. Chest 1994; 105: 132-7.

46. Lissoni P, Meregalli S, Bonetto E, Mancuso M, Brivio F, Colciago M, et al. Radiotherapy-induced lymphocytopenia: changes in total lymphocyte count and in lymphocyte subpopulations under pelvic irradiation in gynecologic neoplasms. J Biol Regul Homeost Agents 2005; 19: 153-8.
47. Gray WC, Hasslinger BJ, Suter CM, Blanchard CL, Goldstein AL, Chretien PB. Suppression of cellular immunity by head and neck irradiation. Precipitating factors and reparative mechanisms in an experimental model. Arch Otolaryngol Head Neck Surg 1986; 112: 1185-90.

48. Verastegui EL, Morales RB, Barrera-Franco JL, Poitevin AC, Hadden J. Long-term immune dysfunction after radiotherapy to the head and neck area. Int Immunopharmacol 2003; 3: 1093-104.

49. Ohzato H, Yoshizaki K, Nishimoto N, Ogata A, Tagoh $\mathrm{H}$, Monden $\mathrm{M}$, et al. Interleukin-6 as a new indicator of inflammatory status: detection of serum levels of interleukin-6 and C-reactive protein after surgery. Surgery 1992; 111: 201-9.

50. Kallio R, Bloigu A, Surcel HM, Syrjälä H. C-reactive protein and erythrocyte sedimentation rate in differential diagnosis between infections and neoplastic fever in patients with solid tumours and lymphomas. Support Care Cancer 2001; 9: 124-8.

51. Brigden ML. Clinical utility of the erythrocyte sedimentation rate. Am Fam Physician 1999; 60: 1443-50.

52. Nozoe T, Saeki H, Sugimachi K. Significance of preoperative elevation of serum C-reactive protein as an indicator of prognosis in esophageal carcinoma. Am J Surg 2001; 182: 197-201.

53. Nozoe T, Matsumata T, Kitamura M, Sugimachi K. Significance of preoperative elevation of serum $\mathrm{C}$-reactive protein as an indicator for prognosis in colorectal cancer. Am J Surg 1998; 176: 335-8.

54. Kodama J, Miyagi Y, Seki N, Tokumo K, Yoshinouchi M, Kobashi Y, et al. Serum C-reactive protein as a prognostic factor in patients with epithelial ovarian cancer. Eur J Obstet Gynecol Reprod Biol 1999; 82: 107-10.

55. Khandavilli SD, Ceallaigh PO, Lloyd CJ, Whitaker $\mathrm{R}$. Serum C-reactive protein as a prognostic indicator in patients with oral squamous cell carcinoma. Oral Oncol 2009; 45: 912-4.

56. Lewis, S.M. Erythrocyte sedimentation rate and plasma viscosity. Association of Clinical Pathologists. Broadsheet 94, June 1980.

57. Hart GD, Soots M, Sullivan J. Significance of extreme elevation of erythrocyte sedimentation rate. Appl Ther 1970; 12: 12-3.

58. Tang JT, Yamazaki H, Nishimoto N, Inoue T, Nose T, Koizumi M, et al. Effect of radiotherapy on serum level of interleukin 6 in patients with cervical carcinoma. Anticancer Res 1996; 16: 2005-8. 
59. Koc M, Taysi S, Sezen O, Bakan N. Levels of some acute-phase proteins in the serum of patients with cancer during radiotherapy. Biol Pharm Bull 2003; 26: 1494-7.

60. Cengiz M, Akbulut S, Atahan IL, Grigsby PW. Acute phase response during radiotherapy. Int $J$ Radiat Oncol Biol Phys 2001; 49: 1093-6.

61. Nimmerjahn F, Ravetch JV. Fc $\gamma$ receptors: old friends and new family members. Immunity 2006; 24: $19-28$.

62. Radaev S, Sun P. Recognition of immunoglobulins by $\mathrm{Fc} \gamma$ receptors. Molecular Immunology 2002; 38: 1073-83.

63. Guyre PM, Campbell AS, Kniffin WD, Fanger MW. Monocytes and polymorphonuclear neutrophils of patients with streptococcal pharyngitis express increased numbers of type I IgG Fc receptors. J Clin Invest 1990; 86: 1892-6.

64. Herra CM, Keane CT, Whelan A. Increased expression of Fcgamma receptors on neutrophils and monocytes may reflect ongoing bacterial infection. J Med Microbiol 1996; 44: 135-40.

65. Leino L, Sorvajarvi K, Katajisto J, Laine M, Lilius EM, Pelliniemi TT, et al. Febrile infection changes the expression of IgG Fc receptors and complement receptors in human neutrophils in vivo. Clin Exp Immunol 1997; 107: 37-43.

66. Qureshi SS, Lewis SM, Gant VA, Treacher D, Davis BH, Brown KA. Increased distribution and expression of CD64 on blood polymorphonuclear cells from patients with the systemic inflammatory response syndrome (SIRS). Clin Exp Immunol 2001; 125: 258-65.

67. Groselj-Grenc M, Ihan A, Derganc M. Neutrophil and monocyte CD64 and CD163 expression in critically ill neonates and children with sepsis: comparison of fluorescence intensities and calculated indexes. Mediators Inflamm 2008; 2008: 202646.

68. Hiesmayr MJ, Spittler A, Lassnigg A, Berger R, Laufer G, Kocher A, et al. Alterations in the number of circulating leucocytes, phenotype of monocyte and cytokine production in patients undergoing cardiothoracic surgery. Clin Exp Immunol 1999; 115: 315-23.

69. Fjaertoft G, Håkansson LD, Pauksens K, Sisask G, Venge P. Neutrophil CD64 (FcgammaRI) expression is a specific marker of bacterial infection: a study on the kinetics and the impact of major surgery. Scand J Infect Dis 2007; 39: 525-35.
70. Nieto A, Sánchez MJ, Martínez C, Castellsagué X, Quintana MJ, Bosch X, et al. Lifetime body mass index and risk of oral cavity and oropharyngeal cancer by smoking and drinking habits. Br J Cancer 2003; 89: 1667-71.

71. Strojan P. Cysteine cathepsins and stefins in head and neck cancer: an update of clinical studies. Radiol Oncol 2008; 42: 69-81.

72. Jurdana M. Cancer cachexia-anorexia syndrome and skeletal muscle wasting. Radiol Oncol 2009; 43: 65-75. 